\title{
Efficacy and safety of eribulin mesylate in advanced soft tissue sarcomas
}

\section{Jonathan Noujaim,}

Salma Alam ${ }^{1}$, Khin Thway ${ }^{1}$,

Robin Lewis Jones ${ }^{1}$

Sarcoma Unit, MaisonneuveRosemont Hospital, Montreal, H1T 2M4, Canada, ' Sarcoma Unit, The Institute of Cancer Research, Royal Marsden Hospital, London, SW3 6JJ, UK

\section{Address for correspondence: Dr. Jonathan Noujaim, \\ Sarcoma Unit, Maisonneuve- Rosemont Hospital, Montreal, H1T 2M4, Canada. \\ E-mail: john.c.njm@gmail.com Dr. Robin Lewis Jones, \\ Sarcoma Unit, The Royal Marsden NHS Foundation Trust, 203 Fulham Road, London SW3 6JJ, UK. \\ E-mail: robin.jones4@nhs.net}

\section{A B S T R A C T}

Despite recent advances in the field, treatment options for metastatic soft tissue sarcoma patients are limited. Eribulin, an antimitotic derived from the natural marine sponge product halichondrin $B$, is currently approved for the treatment of metastatic breast cancer. Following the promising activity of eribulin in sarcoma in a Phase II trial, the drug was recently compared to dacarbazine in pretreated advanced leiomyosarcoma (LMS) and liposarcoma (LPS) patients in a Phase III trial. Eribulin was associated with a significant 2-month improvement in median overall survival compared to dacarbazine (13.5 vs. 11.5 months, heart rate: 0.768 ) despite no documented significant difference in progression-free survival. In a subgroup analysis, the survival advantage associated with eribulin was evident in the LPS subgroup but not in the LMS subgroup. Following these encouraging results, the Food and Drug Administration has approved eribulin for the treatment of advanced LPS for patients who received prior anthracycline chemotherapy. In this short review, we will evaluate the evidence for eribulin in soft tissue sarcoma, highlight its mechanisms of action, and summarize the results of the major preclinical and clinical studies with a particular focus on the results of the Phase III trial.

Key words: Efficacy, eribulin, leiomyosarcoma, liposarcoma, safety

\section{INTRODUCTION}

Soft tissue sarcomas (STS) are rare, heterogeneous connective tissue tumors composed of over fifty different histological subtypes, each with their own clinical behavior and response to systemic therapy. ${ }^{[1]}$ Complete surgical resection with or without radiation therapy is the mainstay of management for localized disease. Despite adequate local control, recurrences are observed in approximately half of patients with high-grade tumors. The outcome of patients with metastatic disease is poor with a median overall survival (OS) estimated to be between 12 and 18 months. ${ }^{[2]}$ Systemic chemotherapy continues to be a palliative measure with doxorubicin with or without ifosfamide remaining the standard first-line regimen. ${ }^{[3]}$ The addition of gemcitabine-docetaxel, trabectedin and pazopanib have expanded the therapeutic armamentarium available to treat metastatic soft tissue sarcoma. ${ }^{[4-6]}$ However, past studies have limited the assessment of the true clinical impact of novel therapies on sarcoma subtype. Clinical trials have recruited a mixture of histologic subtypes thereby complicating the assessment of whether objectified response and outcome were due to the specific treatment or to the specific population

\begin{tabular}{|l|l|}
\hline \multicolumn{2}{|c|}{ Access this article online } \\
\hline Quick Response Code: & Website: \\
\hline & www.jmpo.org \\
\cline { 2 - 2 } & \\
\hline
\end{tabular}

enrolled. In recent years, efforts are now directed into tailoring therapy according to histological subtype. ${ }^{[7]}$ However, there are few data showing an OS benefit for systemic therapy.

Eribulin, a fully synthetic macrocyclic ketone analog of the natural marine sponge product halichondrin $\mathrm{B}$, exerts its anticancer effects by triggering apoptosis of cancer cells following prolonged and irreversible mitotic blockade. ${ }^{[8]}$ The drug has been approved for metastatic breast cancer, based on a Phase III trial randomizing patients to receive eribulin or an investigator's choice of systemic therapy. ${ }^{[0]}$ Compared to the treatment of physician's choice in pretreated locally recurrent and metastatic breast cancer, eribulin showed a 2.5 month OS advantage. Recently, a subsequent Phase III trial in advanced leiomyosarcoma (LMS) and liposarcoma (LPS) has shown a significant 2 months improvement in median OS for patients treated with eribulin compared to dacarbazine despite no documented significant difference in progression-free survival (PFS). ${ }^{[10]}$ The aim of this short review is to evaluate the evidence for eribulin in advanced

\footnotetext{
This is an open access article distributed under the terms of the Creative Commons Attribution-NonCommercial-ShareAlike 3.0 License, which allows others to remix, tweak, and build upon the work non-commercially, as long as the author is credited and the new creations are licensed under the identical terms.
}

For reprints contact: reprints@medknow.com

How to cite this article: Noujaim J, Alam S, Thway K, Jones RL. Efficacy and safety of eribulin mesylate in advanced soft tissue sarcomas. Indian J Med Paediatr Oncol 2016;37:125-30. 
soft tissue sarcoma, with a particular focus on the results of the abovementioned Phase III trial and the potential role of this drug in certain histological subtypes.

\section{IN VITRO AND IN VIVO STUDIES OF ERIBULIN}

Eribulin mesylate is a completely synthetic novel analog of the naturally occurring marine macrolide halichondrin $\mathrm{B}$, initially isolated from the Japanese sponge Halichondria okadai in 1985. ${ }^{[11]}$ Its mechanisms are completely distinct from other known antitubulin agents. It binds with high affinity to microtubule ends, preventing cross-link formations, and resulting in the inhibition of microtubule polymerization rather than shortening, without affecting depolymerization. ${ }^{[12]}$ In addition, it also precipitates the sequestration of tubulin into nonfunctional aggregates. Irreversible complete mitotic block at the G2-M cell transition and disruption of mitotic spindle formation inhibit cancer cell growth. Apoptosis is subsequently triggered following a prolonged and irreversible mitotic blockade. ${ }^{[13]}$ Beyond its antimicrotubule effect, eribulin is also involved in tumor vascular remodeling. ${ }^{[14]}$ Eribulin acts as a potent antivascular drug by decreasing the expression of signaling pathways involved in pericyte-driven angiogenesis (vascular endothelial growth factor, Wnt, Notch, and ephrin). ${ }^{[15]}$ The hypoxic microenvironment created by abnormal tumor vasculature contributes to tumor progression, metastasis, and drug resistance. An increase in the number of microvessels and subsequent tissue perfusion were observed in eribulin-treated tumors. ${ }^{[16]}$ These changes to the microenvironment alleviate the tumor-induced hypoxia and may possibly enhance the efficacy of subsequent drug therapies through the reduction of hypoxia-driven chemoresistance and the enhancement of intratumoral delivery of drugs. Finally, eribulin was also shown to suppress the metastatic ability of breast cancer cells by reversing the epithelial-mesenchymal transition state. ${ }^{[17]}$ However, it is unknown if this mechanism may contribute to the activity of eribulin in sarcoma.

\section{PHASE I TRIALS AND PHARMACOKINETICS STUDIES}

The Phase I eribulin trials are summarized in Table 1. The first Phase I trial of eribulin studied its efficacy and safety on advanced and refractory solid tumors and followed a rapid titration design with real-time pharmacokinetics (PKs) to guide dose escalation. ${ }^{[18]}$ The starting dose was $0.125 \mathrm{mg} / \mathrm{m}^{2} /$ week. Dose-limiting toxicity (DLT) was reached at $2.0 \mathrm{mg} / \mathrm{m}^{2} /$ week subsequent to the development of Grades 3 and 4 neutropenia respectively in two patients. The maximum tolerated dose (MTD) was set at $1.4 \mathrm{mg} / \mathrm{m}^{2} /$ week. The second Phase I trial began dosing of eribulin at $0.25 \mathrm{mg} / \mathrm{m}^{2}$ as 1 -h intravenous infusions on days 1,8 , and 15 of a 28 -day cycle. ${ }^{[19]}$ The MTD of eribulin was determined at $1.0 \mathrm{mg} / \mathrm{m}^{2}$. At $1.4 \mathrm{mg} / \mathrm{m}^{2}$, neutropenia (Grade 4 in two patients and Grade 3 in three patients) was the principal (DLT). Fatigue (53\% overall) and nausea (41\% overall) were the most frequent adverse effects (AEs). A third Phase I trial determined the MTD of eribulin to be $2.0 \mathrm{mg} / \mathrm{m}^{2}$ when administered as a $1-\mathrm{h}$ infusion once every 3 weeks. ${ }^{[20]}$ Finally, a Japanese Phase I trial demonstrated manageable tolerability of eribulin at $1.4 \mathrm{mg} / \mathrm{m}^{2}$ when administered on days 1 and 8 of a 21-day cycle. ${ }^{[21]}$ Neutropenia was again the principal DLT in both those trials. Following the previously described Phase I trials, the recommended dose of eribulin was set at a concentration of $1.4 \mathrm{mg} / \mathrm{m}^{2}$. However, its administration on days 1,8 , and 15 of a 28 -day cycle proved difficult to tolerate. ${ }^{[22]}$ Neutropenia often limited its administration on day 15. Modification of the regimen to a 21-day cycle where eribulin was given on days 1 and 8 was as efficient and better tolerated and was therefore established as the scheduling standard for future Phase II and Phase III trials.

Distribution of eribulin is rapid, and elimination is slow, and its PK is best described by a three-compartment model, with elimination from the central compartment. In a patient with adequate liver and renal functions, eribulin clearance was estimated at $2.98 \mathrm{~L} / \mathrm{h}$ (central volume of distribution was $3.72 \mathrm{~L}$, volumes of two peripheral compartments were $3.60 \mathrm{~L}$ and $126 \mathrm{~L}$ ), and intercompartmental clearances were $2.7 \mathrm{~L} / \mathrm{h}$ and $5.6 \mathrm{~L} / \mathrm{h}$. The inter-individual variation of liver and renal functions can explain the interpatient drug clearance variability (mean 57\%, range 26\%-98\%) described in studies. ${ }^{[23]}$ Any degree of liver impairment decreases the drug clearance and prolongs exposure to eribulin. It is, therefore, recommended to decrease the eribulin dose to $1.1 \mathrm{mg} / \mathrm{m}^{2}$ for patients with mild hepatic

\begin{tabular}{|c|c|c|c|c|c|}
\hline Administration schedule & Patients $(n)$ & Responses & $\operatorname{MTD}\left(\mathrm{mg} / \mathrm{m}^{2}\right)$ & DLT & References \\
\hline Bolus day $1,8,15$ every 28 days & 40 & $2 P R$ & 1.4 & $\begin{array}{l}1 G_{3} \text { febrile neutropenia; } \\
1 G_{4} \text { neutropenia }\end{array}$ & [18] \\
\hline $1 \mathrm{~h}$ infusion day $1,8,15$ every 28 day & 32 & $1 \mathrm{PR}(\mathrm{U})$ & 1.0 & $\begin{array}{l}2 G_{4} \text { neutropenia; } 1 G_{3} \text { fatigue; } \\
3 G_{3} \text { neutropenia }\end{array}$ & [19] \\
\hline $1 \mathrm{~h}$ infusion day 1 every 21 days & 21 & $1 \mathrm{PR}(\mathrm{U})$ & 2.0 & $3 \mathrm{G}_{4}$ febrile neutropenia & {$[20]$} \\
\hline 2-10 min injections day 1,8 every 21 days & 15 & $3 P R$ & 2.0 & $\begin{array}{l}1 \mathrm{G}_{4} \text { neutropenia; } 1 \mathrm{G}_{3} \text { febrile } \\
\text { neutropenia }\end{array}$ & {$[21]$} \\
\hline
\end{tabular}

MTD - Maximum tolerated dose; DLT - Dose limiting toxicity; $u$ - Unconfirmed 
impairment (Child-Pugh A) and to $0.7 \mathrm{mg} / \mathrm{m}^{2}$ for patients with moderate hepatic impairment (Child-Pugh B). Eribulin is to be avoided in patients with severe hepatic impairment. Renal impairment also decreases drug clearances and prolongs exposure, and it is therefore recommended to reduce eribulin to $1 \mathrm{mg} / \mathrm{m}^{2}$ in patients with moderate $(\mathrm{CrCl} 30-50 \mathrm{~mL} / \mathrm{min})$ and severe renal impairment ( $\mathrm{CrCl} 15-30 \mathrm{~mL} / \mathrm{min}) \cdot{ }^{[24]}$

\section{PHASE II TRIAL IN SOFT TISSUE SARCOMA}

The European Organisation of Research and Treatment of Cancer conducted an open-label Phase II trial of eribulin in recurrent soft tissue sarcoma of high or intermediate grade. Enrolled patients received no more than one previous combination chemotherapy or up to two single drugs for the advanced disease. Patients with embryonal rhabdomyosarcoma, chondrosarcoma, osteosarcoma, Ewing family tumors, gastrointestinal stromal tumors, dermatofibrosarcoma protuberans, and inflammatory myofibroblastic tumors were excluded from the trial. Recruited patients were divided into four strata: LPS, LMS, synovial sarcoma (SS), and others. ${ }^{[25]}$ The primary endpoint of the trial was the PFS at 12 weeks. Eribulin was administered intravenously at a concentration of $1.4 \mathrm{mg} / \mathrm{m}^{2}$ over 2-5 min at days 1 and 8 of a 21-day cycle. Response to therapy was assessed using Response Evaluation Criteria In Solid Tumors (RECIST) 1.0. A total of 128 patients were recruited, with 115 patients eligible for analysis.

The median age was 56.7 years and the median time interval from initial diagnosis was 2 years. In total, 37 patients had LPS (24 dedifferentiated, four pleomorphic and six myxoid/round-cell LPSs, two not otherwise specified, and one unknown), forty patients had LMS (including 11 arising from the uterus), 19 patients had SS and 32 patients had other types of soft tissue sarcoma. A total of 616 treatment cycles were administered to 127 patients, with a median number of four cycles per patient. Results are summarized in Table 2. The 12-week progression-free rates (PFRs) were $31.6 \%, 46.9 \%, 21.1 \%$, and $19.2 \%$ respectively for LMS, LPS, SS, and the other subtypes. The median PFS was 2.6 months (95\%confidence interval [CI]: 1.7-6.2) for patients with LPS, 2.9 months (95\%CI: 2.4-4.6) for those with LMS, 2.6 months (95\%CI: 2.3-4.3) for SS and 2.1 months (95\% CI: 1.4-2.9) for other subtypes.

Eribulin treatment in this study mirrored the toxicity profile reported during Phase I trials with only $6 \%$ of recorded Grade 3 febrile neutropenia and $6 \%$ of Grade 3-4 thrombocytopenia. All events of neutropenia and thrombocytopenia were self-limiting. Other common treatment-related nonhematological adverse events reported were fatigue, alopecia, nausea, and sensory neuropathy. Six patients discontinued treatment because of neurotoxic effects, though patients with preexisting Grade 2 sensory neuropathy were allowed to enroll in the trial. Toxicity management included dose reductions and dose delays with 42 (33\%) of 127 patients receiving eribulin at full dose without delay, $33(26 \%)$ of patients having treatment delays, $15(12 \%)$ requiring dose reductions, and $37(29 \%)$ requiring both delays and dose reductions.

Currently, another open-label, multicenter, Phase II trial conducted in Japan, is evaluating the efficacy and safety of eribulin in previously treated subjects with STS. The primary outcome of the trial is PFR 12 weeks. In this trial, patients will be divided into two groups: The first with LPS/LMS and the second with other STS.

\section{PHASE III TRIAL IN LIPOSARCOMA AND LEIOMYOSARCOMA}

The promising results of the Phase II trial in soft tissue sarcoma led to the initiation of a randomized Phase III trial comparing eribulin to dacarbazine in LPS and LMS

\begin{tabular}{|c|c|c|c|c|c|}
\hline \multirow[t]{2}{*}{ Histological subtype } & \multirow[t]{2}{*}{ Patients $(n)$} & \multirow{2}{*}{$\begin{array}{l}\text { Best overall } \\
\text { response (\%) }\end{array}$} & \multirow{2}{*}{$\begin{array}{l}\text { Progression-free } \\
\text { at } 12 \text { weeks, \% }\end{array}$} & \multicolumn{2}{|c|}{$95 \% \mathrm{Cl}$} \\
\hline & & & & Median PFS (months) & 6 months-OS \\
\hline \multirow[t]{3}{*}{ Adipocytic sarcoma } & 32 & $1-(3) C R$ & $46.9(15 / 32)$ & $2.6(1.7-6.2)$ & $74.6(55.5-86.4)$ \\
\hline & & $0-P R$ & & & \\
\hline & & $18(56)$ - SD & & & \\
\hline \multirow[t]{3}{*}{ Leiomyosarcoma } & 38 & $0-C R$ & $31.6(12 / 38)$ & $2.9(2.4-4.6)$ & $86.8(71.2-94 \cdot 3)$ \\
\hline & & $2(5)-P R$ & & & \\
\hline & & $20(53)-S D$ & & & \\
\hline \multirow[t]{3}{*}{ Synovial sarcoma } & 19 & $0-C R$ & $21.1(4 / 19)$ & $2.6(2.3-4.3)$ & $71.1(43.7-86.8)$ \\
\hline & & $1(5)-P R$ & & & \\
\hline & & $8(42)-S D$ & & & \\
\hline \multirow[t]{3}{*}{ Other soft tissue sarcoma } & 26 & $0-C R$ & $19.2(5 / 26)$ & $2.1(1.4-2.9)$ & $52.9(31.2-70.7)$ \\
\hline & & $1(4)-P R$ & & & \\
\hline & & $11(42)-S D$ & & & \\
\hline
\end{tabular}

$\mathrm{Cl}$ - Confidence interval; OS - Overall survival; PFS - Progression-free survival; CR - Complete response; PR - Partial response; SD - Stable disease 
of the intermediate or high grade. ${ }^{[10]}$ Patients previously treated with at least two lines of therapy were randomized to receive either eribulin $1.4 \mathrm{mg} / \mathrm{m}^{2}$ intravenous on day 1 and day 8 every 21 days or dacarbazine $800-1200 \mathrm{mg} / \mathrm{m}^{2}$ on day 1 every 21 days according to the investigator's choice. The response was assessed using RECIST 1.1. The primary endpoint was OS and selected secondary endpoints included PFS and PFRs at 12 weeks.

A total of 594 patients were screened, and 452 patients were randomized. Clinical characteristics were well balanced between both randomized groups. The majority of patients $(78.8 \%)$ were under the age of 65 with a good performance status. LPS and LMS accounted for $67.7 \%$ and $33.8 \%$ of cases, respectively. In the LMS subgroup, $43.1 \%$ of cases were uterine in origin. The study cohort was heavily pretreated with $45.8 \%$ of patients having received more than two prior lines of therapy. Three hundred and fifty-one patients $(77.7 \%)$ received an anthracycline before enrolment.

At the time of data cutoff (January 2015), 357 (79.0\%) patients had died. There was a significant difference in survival between the two arms (median OS for eribulin 13.5 months and dacarbazine 11.5 months, heart rate [HR]: 0.768; 95\%CI: 0.618-0.954, $P=0.0169)$. However, no significant difference in median PFS was observed (2.6 months for both eribulin and dacarbazine, HR: 0.877; 95\% CI: $0.710-1.085, P=0.2287)$. In addition, there was no significant difference in response rates between the two agents (overall response rates $3.9 \%$ vs. $4.9 \%$, stable disease $52.2 \%$ vs. $47.8 \%$ ). In the preplanned OS subgroup analysis, eribulin favored LPS patients (15.6 vs. 8.4 months, HR: 0.511 ; 95\%CI: 0.346-0.753) compared to LMS patients (12.7 vs. 13.0 months, HR: 0.927; 95\%CI: 0.714-1.203). All LPS subtypes benefitted from exposure to eribulin, especially dedifferentiated LPS and pleomorphic LPS. Furthermore, patients with a PS of 0 had a better survival outcome with eribulin (19.9 vs. 13.1 months, HR: 0.579; 95\% CI: $0.407-0.823)$ compared to patients with a PS of 1-2 (9.2 vs. 9.9 months, HR: 1.09; 95\%CI: 0.82-1.44).

No unexpected or previously unreported toxicity was documented for either drug in this randomized trial. Grades 3 and 4 AEs were observed in $38.9 \%$ and $23.9 \%$ of patients in the eribulin group and $35.7 \%$ and $19.2 \%$ in the dacarbazine group. Neutropenia, fatigue and nausea were the most common AEs for both groups. Only 4 (1.8\%) patients developed $\geq$ Grade 3 sensory neuropathy with eribulin. Two patient deaths were attributed to eribulin (one neutropenic sepsis and one septic shock).

\section{DISCUSSION}

The eribulin trial is the first Phase III trial in the last decade that has shown a clinically significant survival benefit in the treatment of advanced soft tissue sarcoma, and these results are clearly very encouraging. However, the discrepancy between the PFS and OS results remain difficult to explain. These findings surprisingly mirrored the results reported from the EMBRACE trial that compared eribulin to a physician's choice of therapy in metastatic breast cancer patients. ${ }^{\left[{ }^{[0]}\right.}$ The superiority of the eribulin arm cannot be explained by the dosing variation of the dacarbazine arm. Although the starting dose of dacarbazine varied according to the investigator's choice, post hoc analysis showed no significant impact on survival. Both eribulin and dacarbazine demonstrated similar response rates and therefore support the findings of similar PFS.

One can hypothesize that posttrial treatments may contribute to the difference of OS. However, the administration of posttrial therapy (including surgery and radiation) was comparable between the two arms of the trial, apart from a higher number of patients in the eribulin arm receiving dacarbazine ( $34.2 \%$ vs. $7.6 \%$, respectively). As it was previously described in preclinical studies, beyond its antimitotic effect, eribulin contributes to vascular remodeling and to decreasing the tumor-induced hypoxic microenvironment. These changes subsequently increase drug delivery. It is, therefore, possible that patients who were previously treated with eribulin were sensitized to posttrial therapies, thereby providing an explanation for the increased survival despite no objectified difference in PFS. Tumor-induced hypoxia is a known mechanism of drug resistance, especially in sarcoma, and correlates with a poor prognosis. ${ }^{[2-28]}$ Another drug, evofosfamide (TH-302), a 2-nitroimidazole prodrug that becomes highly cytotoxic in a hypoxic environment, was shown to be active in soft tissue sarcoma in a Phase II trial. ${ }^{[29]}$ These results support the critical role of hypoxia in the tumorigenicity of sarcoma. The underlying reasons as to why eribulin was more active in LPS (especially dedifferentiated LPS) compared to LMS are elusive. Beyond eribulin's role in alleviating tumor-induced hypoxia, other mechanisms of action, including potentially an immune mechanism, remain speculative. Further translational studies are required to assess other potential mechanisms of action and to evaluate putative markers of response to this agent.

The OS advantage observed in the eribulin Phase III trial contrasts with the results of the Phase III trial comparing trabectedin to dacarbazine in metastatic LMS and LPS and with the results of the PALETTE trial comparing pazopanib to placebo in advanced nonadipocytic soft tissue sarcoma. ${ }^{[5,6]}$ Both patient groups were heavily pretreated. Trabectedin showed a significant benefit in terms of PFS (4.2 vs. 1.5 months; HR: 0.55), but no significant benefit in OS compared to dacarbazine (12.4 vs. 12.9 months; HR: 0.87). In subgroup analysis, 
both LMS and LPS patients had significant benefits in terms in terms of PFS, but no difference in OS compared to dacarbazine. In the PALETTE trial, a significant benefit in PFS (4.6 vs. 1.6 months; HR: 0.31) was documented with no statistical difference in OS (12.5 vs. 10.7 months; HR: 0.86). These results are important to highlight when discussing the cost-effectiveness of eribulin as a new treatment. Compared to previously approved therapies for soft tissue sarcoma, eribulin is the first to demonstrate a statistically significant improvement in OS. Despite the increased OS in breast cancer patients in the EMBRACE trial, eribulin was not considered cost-effective when compared to low-cost chemotherapy drugs used in the comparator arm. ${ }^{[30]} \mathrm{A}$ similar parallel can probably be drawn in sarcoma, as dacarbazine is considered a low-cost drug compared to eribulin. Following the results of the eribulin and trabectedin trials, dacarbazine could be considered cost-effective in treating LMS patients in the third line setting and beyond. However, effective systemic options in LPS are limited, and dacarbazine probably does not have a role in this subtype. Eribulin treated LPS patients (particularly dedifferentiated LPS) had a substantial increase in OS compared to dacarbazine-treated patients. Therefore, eribulin could be considered as a standard therapy in anthracycline-treated LPS patients. Following these encouraging results, the Food and Drug Administration (FDA) has approved eribulin for the treatment of patients with advanced LPS, who received prior anthracycline therapy. It is clear that further work is required to define the cost-effectiveness of sequential systemic therapy in metastatic soft tissue sarcoma in conjunction with improved quality of life assessments.

In summary, anthracycline-based schedules remain the mainstay of first-line therapy, but the optimal sequence of systemic agents in subsequent lines of therapy will need to be accurately defined for soft tissue sarcoma as a whole but also for individual histological subtypes. Eribulin appears to have particular activity in LPS and will probably join the growing number of agents that may potentially be available to treat metastatic sarcoma following first-line therapy, including gemcitabine/docetaxel, pazopanib, dacarbazine, and trabectedin. Eribulin has recently received FDA approval for the treatment of advanced LPS in patients who received prior anthracycline therapy. The cost-effectiveness of the drug will be raised as a potential obstacle to widespread use of the drug. This highlights the need for reproducible quality of life in tools in soft tissue sarcoma, particularly in the context of the toxicity of systemic therapy. However, the Phase III trial has shown a significant survival benefit, and an obvious question is the possible role of eribulin in the neoadjuvant/adjuvant setting and its role in the first-line setting compared to anthracycline therapy in LPS patients. Further studies are required to evaluate putative biomarkers of response to eribulin and the role of this agent in early stage disease.

\section{Acknowledgment}

We acknowledge support from the NIHR Royal Marsden/ ICR Biomedical Research Centre.

Financial support and sponsorship

NIHR Royal Marsden/ICR Biomedical Research Centre.

\section{Conflicts of interest}

There are no conflicts of interest.

\section{REFERENCES}

1. Fletcher CD, Bridge JA, Hogendoorn PC, Mertens F. WHO Classification of Tumours of Soft Tissue and Bone. Pathology and Genetics of Tumours of Soft Tissue and Bone. Lyon: IARC Press; 2013.

2. Italiano A, Mathoulin-Pelissier $S$, Cesne AL, Terrier $P$, Bonvalot $\mathrm{S}$, Collin $\mathrm{F}$, et al. Trends in survival for patients with metastatic soft-tissue sarcoma. Cancer 2011;117:1049-54.

3. Judson I, Verweij J, Gelderblom H, Hartmann JT, Schöffski P, Blay JY, et al. Doxorubicin alone versus intensified doxorubicin plus ifosfamide for first-line treatment of advanced or metastatic soft-tissue sarcoma: A randomised controlled phase 3 trial. Lancet Oncol 2014;15:415-23.

4. Pautier $P$, Floquet $A$, Penel N, Piperno-Neumann S, Isambert N, Rey $A$, et al. Randomized multicenter and stratified phase II study of gemcitabine alone versus gemcitabine and docetaxel in patients with metastatic or relapsed leiomyosarcomas: A Federation Nationale des Centres de Lutte Contre le Cancer (FNCLCC) French Sarcoma Group Study (TAXOGEM study). Oncologist 2012;17:1213-20.

5. Demetri GD, von Mehren $M$, Jones $R L$, Hensley $M L$, Schuetze SM, Staddon A, et al. Efficacy and safety of trabectedin or dacarbazine for metastatic liposarcoma or leiomyosarcoma after failure of conventional chemotherapy: Results of a phase III randomized multicenter clinical trial. J Clin Oncol 2016;34:786-93.

6. van der Graaf WT, Blay JY, Chawla SP, Kim DW, Bui-Nguyen B, Casali PG, et al. Pazopanib for metastatic soft-tissue sarcoma (PALETTE): A randomised, double-blind, placebo-controlled phase 3 trial. Lancet 2012;379:1879-86.

7. Noujaim J, Thway K, Sheri A, Keller C, Jones RL. Histology-driven therapy: The importance of diagnostic accuracy in guiding systemic therapy of soft tissue tumors. Int J Surg Pathol 2016;24:5-15.

8. Towle MJ, Salvato KA, Budrow J, Wels BF, Kuznetsov G, Aalfs $\mathrm{KK}$, et al. In vitro and in vivo anticancer activities of synthetic macrocyclic ketone analogues of halichondrin B. Cancer Res 2001;61:1013-21.

9. Cortes J, O'Shaughnessy J, Loesch D, Blum JL, Vahdat LT, Petrakova K, et al. Eribulin monotherapy versus treatment of physician's choice in patients with metastatic breast cancer (EMBRACE): A phase 3 open-label randomised study. Lancet 2011;377:914-23.

10. Schöffski P, Chawla S, Maki RG, Italiano A, Gelderblom H, Choy $\mathrm{E}$, et al. Eribulin versus dacarbazine in previously treated patients with advanced liposarcoma or leiomyosarcoma: A randomised, open-label, multicentre, phase 3 trial. Lancet 2016;387:1629-37.

11. Swami U, Shah U, Goel S. Eribulin in cancer treatment. Mar Drugs 2015;13:5016-58.

12. Jordan MA, Kamath K, Manna T, Okouneva T, Miller HP, Davis $C$, et al. The primary antimitotic mechanism of action of the synthetic halichondrin E7389 is suppression of microtubule growth. Mol Cancer Ther 2005;4:1086-95.

13. Kuznetsov G, Towle MJ, Cheng H, Kawamura T, TenDyke K, 
Liu D, et al. Induction of morphological and biochemical apoptosis following prolonged mitotic blockage by halichondrin B macrocyclic ketone analog E7389. Cancer Res 2004;64:5760-6.

14. Dybdal-Hargreaves NF, Risinger AL, Mooberry SL. Eribulin mesylate: Mechanism of action of auniquemicrotubule-targeting agent. Clin Cancer Res 2015;21:2445-52.

15. Agoulnik SI, Kawano S, Taylor N, Oestreicher J, Matsui J, Chow J, et al. Eribulin mesylate exerts specific gene expression changes in pericytes and shortens pericyte-driven capillary network in vitro. Vasc Cell 2014;6:3.

16. Funahashi $\mathrm{Y}$, Okamoto $\mathrm{K}$, Adachi $\mathrm{Y}$, Semba $T$, Uesugi M, Ozawa $Y$, et al. Eribulin mesylate reduces tumor microenvironment abnormality by vascular remodeling in preclinical human breast cancer models. Cancer Sci 2014;105:1334-42.

17. Yoshida T, Ozawa Y, Kimura T, Sato Y, Kuznetsov G, $\mathrm{Xu} \mathrm{S}$, et al. Eribulin mesilate suppresses experimental metastasis of breast cancer cells by reversing phenotype from epithelial-mesenchymal transition (EMT) to mesenchymal-epithelial transition (MET) states. $\mathrm{Br} \mathrm{J}$ Cancer 2014;110:1497-505.

18. Synold TW, Morgan RJ, Newman EM, Lenz HJ, Gandara DR, Colevas AD, et al. A Phase I Pharmacokinetic and Target Validation Study of the Novel Anti-Tubulin Agent E7389: A California Cancer Consortium Trial. Proceedings of the ASCO Annual Meeting; Orlando, FL, USA; 13-17 May, 2005.

19. Goel S, Mita AC, Mita M, Rowinsky EK, Chu QS, Wong $\mathrm{N}$, et al. A phase I study of eribulin mesylate (E7389), a mechanistically novel inhibitor of microtubule dynamics, in patients with advanced solid malignancies. Clin Cancer Res 2009;15:4207-12.

20. Tan AR, Rubin EH, Walton DC, Shuster DE, Wong YN, Fang $\mathrm{F}$, et al. Phase I study of eribulin mesylate administered once every 21 days in patients with advanced solid tumors. Clin Cancer Res 2009;15:4213-9.

21. Mukohara $T$, Nagai $S$, Mukai H, Namiki M, Minami H. Eribulin mesylate in patients with refractory cancers: A Phase I study. Invest New Drugs 2012;30:1926-33.

22. Vahdat LT, Pruitt B, Fabian CJ, Rivera RR, Smith DA, Tan-Chiu $\mathrm{E}$, et al. Phase II study of eribulin mesylate, a halichondrin B analog, in patients with metastatic breast cancer previously treated with an anthracycline and a taxane. $\mathrm{J}$ Clin Oncol 2009;27:2954-61.

23. Jansen $M$, Vernaz-Gris $M$, Desjardins $C$, Wong $N$, Campone $M$, Cortes J, et al. Population Pharmacokinetics (PPK) of Eribulin Mesylate in Patients with Locally Advanced or Metastatic Breast Cancer (MBC). Proceedings of the ASCO Annual Meeting; Orlando, FL, USA; 29 May-2 June, 2009.

24. Tan AR, Sarantopoulos J, Lee L, Reyderman L, He Y, Olivo MS, et al. Pharmacokinetics (PK) of Eribulin Mesylate in Cancer Patients (Pts) with Normal and Impaired Renal Function. Proceedings of the ASCO Annual Meeting; Chicago, IL, USA; 30 May-3 June, 2014.

25. Schöffski P, Ray-Coquard IL, Cioffi A, Bui NB, Bauer S, Hartmann JT, et al. Activity of eribulin mesylate in patients with soft-tissue sarcoma: A phase 2 study in four independent histological subtypes. Lancet Oncol 2011;12:1045-52.

26. Nordsmark M, Alsner J, Keller J, Nielsen OS, Jensen OM, Horsman MR, et al. Hypoxia in human soft tissue sarcomas: Adverse impact on survival and no association with p53 mutations. Br J Cancer 2001;84:1070-5.

27. Rajendran JG, Wilson DC, Conrad EU, Peterson LM, Bruckner JD, Rasey JS, et al. [(18) F] FMISO and [(18) F] FDG PET imaging in soft tissue sarcomas: Correlation of hypoxia, metabolism and VEGF expression. Eur J Nucl Med Mol Imaging 2003;30:695-704.

28. Detwiller KY, Fernando NT, Segal NH, Ryeom SW, D'Amore PA, Yoon SS. Analysis of hypoxia-related gene expression in sarcomas and effect of hypoxia on RNA interference of vascular endothelial cell growth factor $A$. Cancer Res 2005;65:5881-9.

29. Chawla SP, Cranmer LD, Van Tine BA, Reed DR, Okuno SH, Butrynski JE, et al. Phase II study of the safety and antitumor activity of the hypoxia-activated prodrug $\mathrm{TH}-302$ in combination with doxorubicin in patients with advanced soft tissue sarcoma. J Clin Oncol 2014;32:3299-306.

30. Lopes G, Glück S, Avancha K, Montero AJ. A cost effectiveness study of eribulin versus standard single-agent cytotoxic chemotherapy for women with previously treated metastatic breast cancer. Breast Cancer Res Treat 2013;137:187-93. 